УДК 339.5(517.4)

DOI dx.doi.org/10.24866/1813-3274/2019-3/29-36

В. О. Намжилова ${ }^{1}$, Бурятский научный центр СО РАН, Улан-Удэ, Россия E-mail: dayavika@yandex.ru

\title{
СОСТОЯНИЕ И ПЕРСПЕКТИВЫ ВНЕШНЕТОРГОВОЙ ДЕЯТЕЛЬНОСТИ АВТОНОМНОГО РАЙОНА ВНУТРЕННЯЯ МОНГОЛИЯ
}

Аннотащия. Предметом исследования стали внешнеторговые связи китайского региона - Автономного района Внутренняя Монголия (АРВМ). Рассматривая итоги внешнеторговой деятельности за последние два десятилетия, автор отмечает, что в годы высокой положительной экономической динамики АРВМ внешнеторговая квота региона, напротив, имела тенденцию к сокращению. Анализ географической структуры внешней торговли АРВМ свидетельствует о растущей роли сопредельных стран - Монголии и России. Подчёркнуты приоритеты внешнеторговой деятельности АРВМ, озвученные в апреле 2019 г. на втором международном форуме «Один пояс, один путь». Регион намерен продвигать на мировые рынки продукцию своих приоритетных отраслей промышленности, а в импорте больше сосредоточиться на природных ресурсах, включая ввоз угля, нефти, железной руды, древесины.

Ключевые слова: АРВМ, внешняя торговля, внешнеторговая квота, географическая структура, экспорт, поставка электроэнергии, импорт природных ресурсов, выставочная деятельность, китайско-монгольское ЭКСПО, приоритеты внешнеторговой деятельности.

\footnotetext{
${ }^{1}$ Виктория Очировна Намжилова, кандидат экономических наук, научный сотрудник, Бурятский научный центр СО РАН, Улан-Удэ, Россия.

Для цитирования: Намжилова В. О. Состояние и перспективы внешнеторговой деятельности Автономного района Внутренняя Монголия // Азиатско-Тихоокеанский регион: экономика, политика, право. 2019. № 3. С. 29-36.
}

(C) Намжилова В. О., 2019 
Victoria O. Namzhilova ${ }^{1}$, Buryat Scientific Centre of SB RAS, Ulan-Ude, Russia E-mail: dayavika@yandex.ru

\section{FOREIGN TRADE OF INNER MONGOLIA AUTONOMOUS REGION: CONDITIONS AND PROSPECTS}

Abstract. The study researches foreign trade relations of the Chinese region - Inner Mongolia Autonomous Region (IMAR). The article discusses the results of foreign trade over the past two decades. The author notes that, in the years of high positive economic dynamics of IMAR, the foreign trade quota of the region, on the contrary, tended to decrease. Analysis of the geographical structure of foreign trade indicates the growing role of neighboring countries - Mongolia and Russia, especially in terms of imports of natural resources. The foreign trade priorities of IMAR, announced in April 2019 at the second international forum "One Belt, One Road", are highlighted. The region intends to export the products of its priority industries to world markets, and to import natural resources, including the import of coal, oil, iron ore, and wood.

Keywords: IMAR, foreign trade, foreign trade quota, geographical structure, export, electric power transmission, import of natural resources, exhibition activities, ChinaMongolia EXPO, foreign trade priorities.

За годы реформ и открытости внешнеторговые связи Автономного района Внутренняя Монголия (АРВМ) развивались под влиянием политических и экономических мер, принимаемых центральным правительством. Реализация политики внешней открытости началась здесь намного позднее, чем в приморских провинциях КНР - с временным лагом более десяти лет. Периферийное положение автономного района с неразвитой инфраструктурой внешней торговли, слабые импульсы к сотрудничеству со стороны России и Монголии также стали факторами, тормозящими развитие внешних связей АРВМ [1]. При этом продвижение собственного экспорта в значительной мере было ограничено уровнем развития экономики и носило узкоспециализированный характер: на мировом рынке конкурентоспособным товаром местного производства были, главным образом, изделия из кашемира. Тем не менее, торговля с зарубежными странами развивалась стабильно с положительной динамикой, география стран расширялась.

\footnotetext{
${ }^{1}$ Victoria O. Namzhilova, Candidate of Sciences (Economics), Research Fellow, Buryat Scientific Centre of SB RAS, Ulan-Ude, Russia.

For citing: Namzhilova V.O. Foreign trade of Inner Mongolia Autonomous Region: conditions and prospects // PACIFIC RIM: Economics, Politics, Law. 2019. № 3. P. 29-36.
} 
В 2018 г. внешнеторговый оборот АРВМ превысил 15 млрд долл. (103,4 млрд юаней), увеличившись в 7,7 раз к показателю 2000 г. В масштабах Китая эти объёмы более чем скромны и составляют менее $1 \%$ общенационального показателя. По внешнеторговому обороту АРВМ занимает 25-е место в стране, меньший уровень внешней торговли показывают только провинции Хайнань, Гуйчжоу, Ганьсу, Цинхай, а также Нинся-Хуэйский и Тибетский автономные районы. Согласно таможенной статистике, в 2018 г. темпы роста внешней торговли АРВМ (9,9\%) стали самыми высокими в стране, а товарооборот с зарубежными странами достиг исторического рекорда, поскольку впервые превысил планку в 100 млрд юаней $(15,68$ млрд долл.) [2].

Структура внешнеторгового баланса АРВМ характеризуется постоянно растущим отрицательным сальдо. Если показатели экспорта и импорта в 2000 г. были сопоставимы - на уровне одного млрд долл., то к 2018 г. импорт значительно превышает экспорт (табл. 1).

Таблица 1

Внешнеторговый оборот АРВМ в 2000-2018 гг., млн долл. США

\begin{tabular}{|c|l|l|l|l|l|}
\hline Год & $\begin{array}{c}\text { Внешняя } \\
\text { торговля }\end{array}$ & \multicolumn{1}{|c|}{ Экспорт } & \multicolumn{1}{|c|}{ Импорт } & \multicolumn{1}{|c|}{ Сальдо } & $\begin{array}{c}\text { Внешнеторговая } \\
\text { квота, \% }\end{array}$ \\
\hline 2000 & 2035,96 & 1021,85 & 1014,11 & 7,74 & 10,96 \\
\hline 2005 & 5161,90 & 2064,89 & 3097,01 & $-1032,12$ & 10,66 \\
\hline 2010 & 8718,94 & 3334,85 & 5384,09 & $-2049,24$ & 4,94 \\
\hline 2015 & 12783,91 & 5673,44 & 7110,47 & $-1437,03$ & 4,44 \\
\hline 2016 & 11701,00 & 4471,00 & 7230,00 & $-2759,00$ & 4,26 \\
\hline 2017 & 13873,52 & 4877,96 & 8995,56 & $-4117,60$ & 5,84 \\
\hline 2018 & 15686,55 & 5751,68 & 9934,87 & $-4183,19$ & 5,98 \\
\hline
\end{tabular}

Источник: [3]

В отличие от приморских провинций Китая, где многие производства изначально в ходе экономических преобразований создавались с ориентацией на экспорт, в АРВМ формировалась отраслевая структура, обеспечивающая удовлетворение внутреннего спроса. Это были в основном отрасли тяжёлой промышленности, связанные с добычей и первичной переработкой природных ресурсов. В годы «энергетического бума» в 2000-е гг. высокая ориентация экономики АРВМ на внутренний рынок Китая стала ещё более очевидной: удельный вес внешнеторгового оборота в валовом региональном продукте, характеризующий внешнюю открытость экономики региона, снизился с 10,9\% в 2000 г. до 4,9\% в 2010 г. На сегодняшний день этот показатель составляет менее 6\% и является одним из самых низких не только среди приграничных регионов, но и в целом по стране (к примеру, внешнеторговая квота в среднем по Китаю в 2018 г. составила 33,9\%). 
Географическая структура внешней торговли АРВМ представлена очень широко и охватывает более чем 160 стран и регионов мира. Примечательно, что значительный рост импорта из сопредельных стран в последние годы меняет географию внешнеторгового оборота АРВМ, где совокупная доля Монголии и России приблизилась к 50\%. Помимо этого, традиционно стабильные торгово-экономические отношения связывают регион с такими странами, как Австралия, США, Япония, Вьетнам, Иран (рис. 1). Доля остальных стран составляет около $1 \%$ и менее.

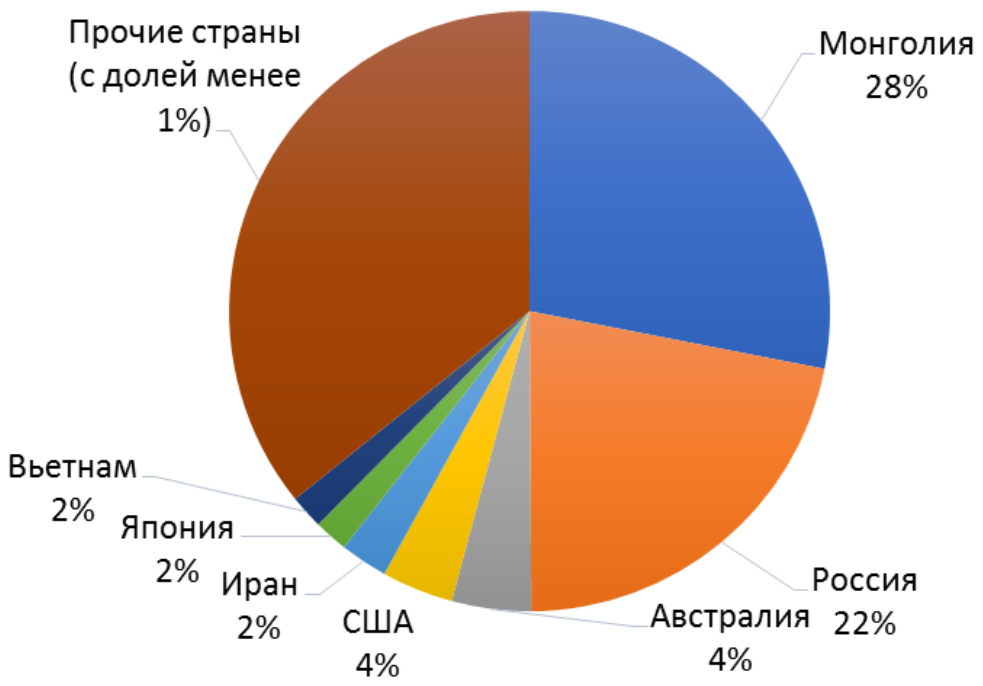

Puc. 1. Географическая структура внешней торговли АРВМ в 2018 г., доля стран в \% (Источник: [4])

Во всём многообразии внешнеторговых связей АРВМ особо следует выделить его торговлю с Монголией, поскольку роль региона в монголо-китайских экономических отношениях крайне важна. Имея протяженную границу с Монголией с девятью пограничными переходами, АРВМ обеспечивает до 60\% внешней торговли между двумя странами. Участие региона в российско-китайской торговле намного скромнее: на АРВМ приходится до 3\% торговли между Россией и Китаем. В целом, данные последних лет показывают, что торговля АРВМ с сопредельными странами формируется за счёт растущего импорта (табл. 2).

В 2018 г. совокупный экспорт АРВМ составил 5,7 млрд долл., или 37,9 млрд юаней (рост на 14,4\%). Товарная структура регионального экспорта представлена различными товарами, включая сельскохозяйственную продукцию, стальные изделия, механизмы и электрооборудование, а также органические химикаты (рис. 2). На мировом рынке высоким спросом пользуется продукция сталелитейного гиганта 
Baotou Steel: сталь для автомобильной промышленности, бытовых электроприборов, нефтегазового сектора, судостроения и строительства, а также специальные легированные стали. Основными рынками сбыта традиционно являются Южная Корея и Европа, но в последние годы экспорт осваивает новые рынки в ЮгоВосточной Азии, Латинской Америке, а также на Ближнем Востоке.

Таблииа 2

\section{Внешнеторговый оборот АРВМ с сопредельными странами,} млн долл. США в текущих ценах

\begin{tabular}{|l|l|l|l|l|}
\hline \multicolumn{1}{|c|}{ Год } & \multicolumn{1}{c|}{ ВТО, всего } & \multicolumn{1}{c|}{ Экспорт } & \multicolumn{1}{c|}{ Импорт } & Сальдо \\
\hline \multicolumn{5}{|l|}{ Монголия } \\
\hline 2016 & 2807,00 & 409,00 & 2398,00 & $-1989,00$ \\
\hline 2017 & 3909,18 & 415,12 & 3494,06 & $-3078,94$ \\
\hline 2018 & 4965,24 & 467,50 & 4497,74 & $-4030,24$ \\
\hline Россия & 2773,00 & 628,00 & 2145,00 & $-1517,00$ \\
\hline 2016 & 2998,35 & 406,18 & 2592,17 & $-2185,99$ \\
\hline 2018 &
\end{tabular}

Источник: [4]

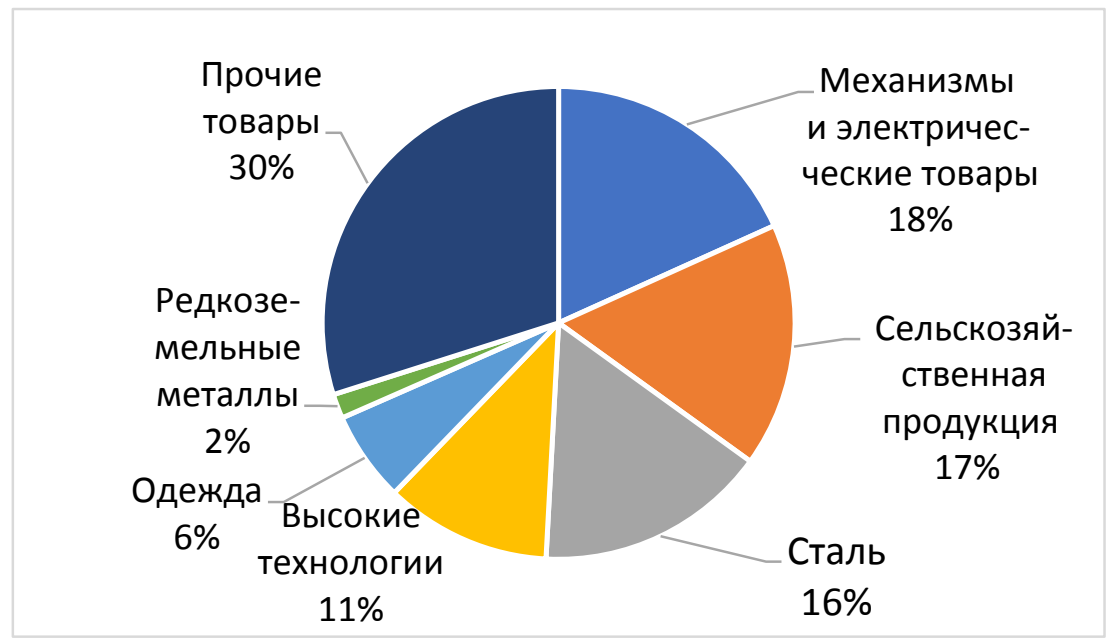

Рис. 2. Товарная структура экспорта АРВМ в 2018 г. (Источник: [4])

Особенной статьёй экспорта АРВМ является поставка электроэнергии в южные аймаки Монголии, где ведётся масштабная разработка месторождений угля, железной руды, золота, меди. При этом экспорт электроэнергии растёт и по прогнозам будет только расширяться [5]. Так, если за первые четыре месяца 2017 г. по се- 
ми трансграничным линиям электропередач было поставлено 103,8 млн кВт/ч, то за первое полугодие 2019 г. через один только пограничный переход Ганцмод было поставлено 649 млн кВт/ч на общую сумму 390 млн юаней [6].

Мы уже отмечали, что АРВМ значительно увеличивает импорт в последние годы. В 2018 г. импорт составил 9,9 млрд долл., или 65,57 млрд юаней, рост к предыдущему году составил 7,5\%. АРВМ специализируется на ввозе угля, медной руды, железной руды и других сырьевых товаров, в большинстве своём из соседней Монголии (рис. 3). По прогнозам, развитие добывающих производств в Монголии и поставки полезных ископаемых с осваиваемых месторождений Оюутолгой и Тавантолгой в ближайшем будущем будут расширяться [7].

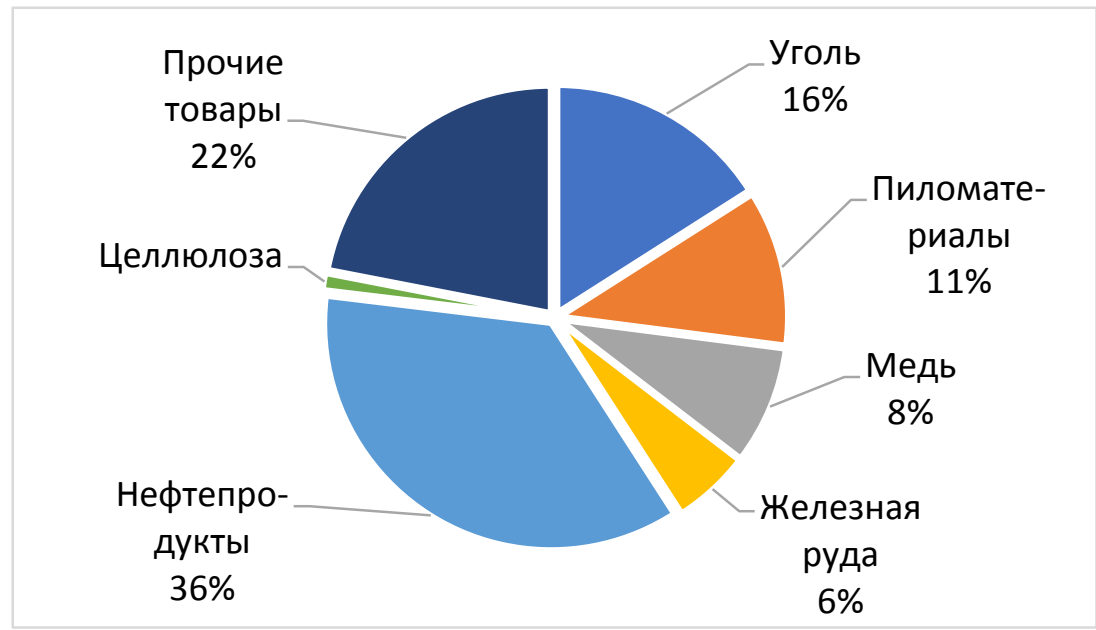

Рис. 3. Товарная структура импорта АРВМ в 2018 г. (Источник: [4)]

Необходимо отметить, что в целях расширения внешнеторговых связей большое развитие получает выставочная деятельность. В приграничном городе Маньчжурия регулярно проводится Китайская (Маньчжурская) северная международная научнотехническая выставка. Мероприятие проводится Министерством науки и техники КНР и является специализированной выставкой научно-технических достижений и инновационных технологий. Более 200 участников из России, Монголии, Таиланда, Индии, Дании, Германии и других стран презентуют новинки в сфере науки, техники, пищевой и сельскохозяйственной отрасли. Китайские участники выставки представляют различные строительные материалы, деревообрабатывающие машины, автомобили и автозапчасти, достижения сельского хозяйства и пищевые продукты.

В 2015 г. дан старт китайско-монгольскому ЭКСПО, которое является важной платформой для развития экономического сотрудничества и культурного обмена 
Намжилова В. О. Состояние и перспективы внешнеторговой деятельности Автономного района Внутренняя Монголия

между Китаем и Монголией. Наиболее высокий интерес бизнес-сообщества обеих стран проявляют в области энергетики, обработки сельскохозяйственной и животноводческой продукции, торговли и логистики, строительства инфраструктуры. Если первые два ЭКСПО (2015 и 2017 гг.) прошли в г. Хух-Хото, то третье китайско-монгольское ЭКСПО в 2019 г. прошло в г. Улаанцав (кит. Уланчаб) - крупном формирующемся транспортном узле АРВМ. С каждым разом повестка ЭКСПО расширяется, включая Совещание по торгово-экономическому сотрудничеству Монголии, Гонконга, Макао и АРВМ, Форум по вопросам регионального сотрудничества Северо-Восточной Азии, Китайско-монгольский форум по стандартизации, Форум по сотрудничеству в оказании правовых услуг Монголии и Китая в торгово-экономической сфере, Китайско-монгольский форум по внедрению технологий и инновационному сотрудничеству и т.д. Помимо указанных крупнейших мероприятий в АРВМ проводится множество других международных выставок и тематических форумов, способствующих налаживанию плодотворных связей с зарубежными партнёрами, развитию внешнеторгового потенциала региона.

Приоритеты внешнеторговой деятельности АРВМ были озвучены в апреле 2019 г. на втором международном форуме «Один пояс, один путь». Регион намерен продвигать на мировые рынки продукцию своих приоритетных отраслей промышленности (металлургия, переработка сельскохозяйственной продукции, химическая промышленность и др.), а в импорте больше сосредоточиться на природных ресурсах, включая ввоз угля, нефти, железной руды, древесины [8]. Таким образом, заявленная сырьевая направленность импорта свидетельствует о готовности осуществлять переработку и создавать добавленную стоимость. Представляется, что внешнеторговая деятельность АРВМ будет рассматриваться как один из драйверов экономики региона, потому главный тренд на ближайшие годы - наращивание товарооборота. При этом сопредельные Монголия и Россия представляют интерес, главным образом, как поставщики природных ресурсов. Инициируемые Китаем инфраструктурные проекты в рамках создания трехстороннего экономического коридора лишь подтверждают эти намерения.

\section{Список литературы}

1. Намжилова, В. О. Экономическое развитие Автономного района Внутренняя Монголия в начале XXI века // Проблемы Дальнего Востока. - 2019. - № 3. C. $73-81$.

2. Темпы роста внешнеторгового оборота АРВМ в 2018 г. стали самыми высокими в Китае // Информационное агентство Жэньминь ван. - URL: http://nm.peop le.com.cn/n2/2019/0208/c196667-32618589.html (дата обращения: 30.03.2019). - Кит.

3. Государственное статистическое управление KHP. - URL: http://data.stats.gov.cn/easyquery.htm?cn=E0103 (дата обращения: 31.12.2019). - Кит.

4. Данные Статистического управления APBM. - URL: http://tj.nmg.gov.cn/nds j/index.html (дата обращения: 31.12.2019). - Кит. 
5. Заместитель председателя АРВМ Чжан Цзяньмин: в прошлом году $2 / 3$ внешней торговли АРВМ пришлось на страны «Одного пояса и Одного пути». URL: http://finance.sina.com.cn/wm/2017-05-24/doc-ifyfkqwe0981333.shtml (дата обращения: 30.03.2019). - Кит.

6. Поставки электроэнергии в Монголию через пограничный переход Ганцмод превысили 7 млрд. кВт/ч. - URL: http://www.nmg.gov.cn/art/2019/7/24/art_1 52_273636.html (дата обращения: 12.10.2019). - Кит.

7. Отгонсайхан, Н. Прогноз экспорта и импорта товаров Монголии // Известия Иркутской государственной экономической академии (Байкальский государственный университет экономики и права). - 2012. - № 6. - С. 24.

8. Продвижение электроэнергетических и угольных компаний АРВМ на зарубежные рынки. - URL: https://finance.sina.com.cn/roll/2019-04-24/docihvhiewr7976146.shtml (дата обращения: 31.12.2019). - Кит.

\section{References}

1. Namzhilova V.O. Ekonomicheskoe razvitie Avtonomnogo raiona Vnutrennyaya Mongoliya v nachale XXI veka [Economic development of the Autonomous Region of Inner Mongolia at the beginning of the XXI century]. Problemy Dal'nego Vostoka, 2019, no. 3, pp. 73-81.

2. The growth rate of foreign trade turnover of AWP in 2018 became the highest in China. Renmin Wang Information Agency. Available at: http://nm.people.com.cn/n2/20 19/0208/c196667-32618589.html (accessed 30 March 2019). (In Chinese).

3. State Statistical Office of the PRC. Available at: http://data.stats .gov.cn/easyquery.ht m?cn=E0103 (accessed 31 December 2019). (In Chinese).

4. Data from Shenyang Customs for January-November 2018. Available at: http://tj.nmg.gov.cn/ndsj/index.html (accessed 31 December 2019). (In Chinese).

5. Deputy Chairperson of AWPM Zhang Jianming: Last year, 2/3 of the foreign trade of AWPM fell on the countries of "One Belt and One Way». Available at: http://finance.sina.com.cn/wm/2017-05-24/doc-ifyfkqwe0981333.shtml (accessed 30 March 2019). (In Chinese).

6. Electricity supplies to Mongolia through the Gantsmod border crossing exceeded 7 billion kW/h. Available at: http://www.nmg.gov.cn/art/2019/7/24/art_152_273636.html (accessed 12.10.2019). (In Chinese).

7. Otgonsayhan N. Prognoz eksporta i importa tovarov Mongolii [Forecast of export and import of goods of Mongolia]. Izvestiya Irkutskoi gosudarstvennoi ekonomicheskoi akademii (Baikal'skii gosudarstvennyi universitet ekonomiki i prava), 2012, no. 6, p. 24.

8. Promotion of ARVM Electricity and Coal Companies to Foreign Markets Available at: https://finance.sina.com.cn/roll/2019-04-24/doc-ihvhiewr7976146.shtml (accessed 31 December 2019). (In Chinese). 